\title{
Mobile technologies as a catalyst for pedagogic innovation within teacher education
}

\begin{abstract}
This paper reviews the use of mobile technologies within teacher education at the University of Northampton. In order to develop a strong commitment to digital literacy the School of Education is using sets of teaching iPads with trainee teachers and has allocated an iPad to every member of academic staff. Experiences from mobile technology projects involving ITT students, primary teachers and academics are shared in order to illustrate how mobile technologies have been a catalyst for new pedagogies based on a social constructivist model of learning in our teacher education programmes. We aim to develop creative, selfdirected learners who can work in collaborative teams within a professional community of teachers, academics and students. We have considered ways in which mobile devices extend learning beyond taught sessions, and how the use of apps to make shareable digital artefacts can lead to purposeful engagement. To this end, the School of Education is focusing on a set of core apps that facilitate the creation, collaboration, curation, and capture of content.
\end{abstract}

\section{INTRODUCTION}

The University of Northampton is making increased use of blended learning approaches in preparation for a move to a new campus in 2018, which will involve a reduction in space and an absence of lecture theatres. Within this context of change, the School of Education is exploring approaches to teaching and learning with mobile technologies based on a social constructivist model of learning that moves away from teacher directed pedagogy towards a flexible learner-centred approach. The idea of using mobile devices to facilitate selfdirected and social learning is a central feature of our approach, however it may necessitate a redefinition of teaching and learning roles (Caldwell \& Heaton, 2015). In this paper, I will draw upon some examples from our recent practice to consider ways in which mobile technologies have acted as a catalyst in the process of pedagogical innovation. Innovation is an elusive concept and what is innovative to one learning context may not be to another, however, we have chosen to emphasise the practical application of ideas, echoing Denning's definition of innovation as 'the adoption of a new practice in a community' (Denning 2004) and Gulbrandsen and Aanstad's (2014) suggestion that innovation is something new that is put to practical use.

The author is a Senior Lecturer in the Teacher Education Division at the University 


\section{BACKGROUND}

\section{Technology driven innovation}

Although technology is generally recognised to have the power to transform education (Puentendra, 2006; Cope \& Kalantzis, 2008) several educators express the opinion that a technology-rich learning environment requires a shift in roles and responsibility for learning, and that achieving this is a challenge for teachers (Chandra \& Mills, 2015). Luckin (2010) suggests that this shift can be characterised as one from Pedagogy (teacher-determined) to Heutagogy (learnerdetermined). One of the challenges facing university lecturers in the field of teacher education is how to encourage student teachers and in-service teachers to explore, adopt and apply new approaches to teaching and learning (Moats, 2014; Livingstone, 2014). Because of this, we need to find ways to develop and disseminate pedagogical innovation that increase the likelihood of the transfer of new approaches to teaching and learning from university to classroom.

Many university programmes now embrace the use of new technologies such as mobiles to support and engage in teaching and learning (Bertarelli et al. 2011), though some writers would argue that many universities still fail to grasp the opportunities afforded by technology because of a lack of knowledge of what can be achieved through its use (Selwyn 2007; Twining et al., 2015). Nevertheless, writers on the topic of teaching and learning suggest that the case for the positive impact of technology on teaching and learning is considerable and compelling (e.g. Tamin et al., 2011; Higgins, et al. 2012) not least because it enables universities to reach out to new and larger audiences and for learning to take place in new ways. Within our context, we have found that online learning communities and social networking tools such as blogs provide a visual platform for sharing digital artefacts and promote the concept of social learning. In this paper, we will consider how learning communities can complement the use of mobile technologies in Teacher Education.

\section{Learning communities}

A learning community can be viewed as a social grouping that actively seeks to co-construct knowledge and in which learners are more in control of their learning journeys in comparison with traditional methods of teaching such as lectures or seminars (Oliver \& Herrington, 2000). Belonging to a learning community is said to give increased agency to learners, enabling them to take collective responsibility for determining what they need to know and cutting across boundaries and formal structures (Wenger, 2011). In theory, learning communities should provide a way of developing and sharing collective knowledge, improving both the personal knowledge of the participants and their knowledge within the domain (Wenger \& Lave, 1991).

Since Wenger's early work on social learning (Wenger, 1991) there has been a widespread increase in online learning and in the use of online learning communities as an instructional method, (Ozturk \& Ozcinar, 2013). Online 
learning communities have the potential to link people across time zones and to remove geographical boundaries (Wenger et al. 2002; Gannon-Leary \& Fonainha, 2007). When combined with mobile technologies, they have added communicative potential, giving learners a measure of control over the pace and place of learning, and a degree of engagement that traditional approaches to teaching may not afford.

However, many studies note that some face to face contact can be a strength and make a case for multimodal learning, mixing physical interaction with asynchronous learning (Hammond, 1998). Contemporary learning communities may thus combine physical and virtual spaces and make use of a range of social media and networking technologies. It may be that one of the reasons for a lack of hard evidence regarding the efficacy of using learning communities to bring about pedagogic innovation is the difficulty of analysing the many modes in which such communities interact (e.g., virtual meetings mixed with physical meetings, synchronous interactions mixed with asynchronous interactions, text-based posts mixed with multimedia posts). In our experience, mobile technologies have functioned as the glue pulling together this varied activity.

\section{Mobile Technologies in Education}

Many researchers highlight the potential for mobile technologies to offer unique learning benefits (Heinrich, 2012, Alberta, 2012, Burden et al., 2012). It has been suggested that iPads can promote personalised and learner-centred approaches (Pegrum et al., 2013), increase independence (Alberta, 2012), enhance collaboration (Henderson and Yeow, 2012) and extend boundaries of time and place (Pachler et al., 2009, Clarke, 2012).

Alongside the evidence of impact on student learning, research indicates that the use of iPads may redefine the teacher's role by increasing peer-to-peer learning (Burden et al, 2012). Several studies suggest that the devices alter not only the way teachers teach but also their perceptions of themselves and their pedagogy (Burden et al., 2012, Pachler et al., 2010). These researchers identify a potential transfer in agency from teacher to student and an increase in pupil autonomy and engagement, which may result in significant pedagogical shifts (Melhuish and Falloon, 2010).

In learning and teaching environments then, mobiles have the potential to 'contribute simultaneously to pedagogical innovation and to transformed practice' (Danaher et al. 2009, p.1). And as Hwang et al. (2015 p.1) acknowledge in their discussion of 'seamless flipped learning', a classroom enhanced with mobile technology can facilitate across learning contexts, times, and social settings. Along with other researchers, (Song, 2014; Kong \& Song, 2015), Hwang et al. (2015) note that good use of multimedia is a key feature of successful flipped learning and that multimedia apps on mobile devices make it easier to engage with, revise and share content.

An Australian study of pre-service teachers recognised that iPads could support trainee teachers' learning by developing understanding of both subject knowledge and pedagogy, as well as by helping them to stay connected (Pegrum et al, 2013). 
Recommendations from this research were for lecturers to model reflective practice across formal and informal contexts, and demonstrate the benefits of personal learning networks. This is something we have sought to do by giving our students first hand experience of sharing creative content within an active learning community.

I will provide examples of how some of these affordances of iPads, such as increased connectivity, mobility, ubiquitous access and the potential to make media-rich digital artefacts, have acted as a catalyst for our academices, pre- and in-service teachers to develop and document their mobile learning pedagogies.

\section{EXAMPLES FROM PRACTICE: STUDENTS USING IPADS}

\section{Example 1. Flipped learning in Initial Teacher Training (ITT)}

Firstly I will share some examples of iPad use within our initial teacher training modules and illustrate how the combined use of blogs and online communities supports students' developing understanding of pedagogy and practice.

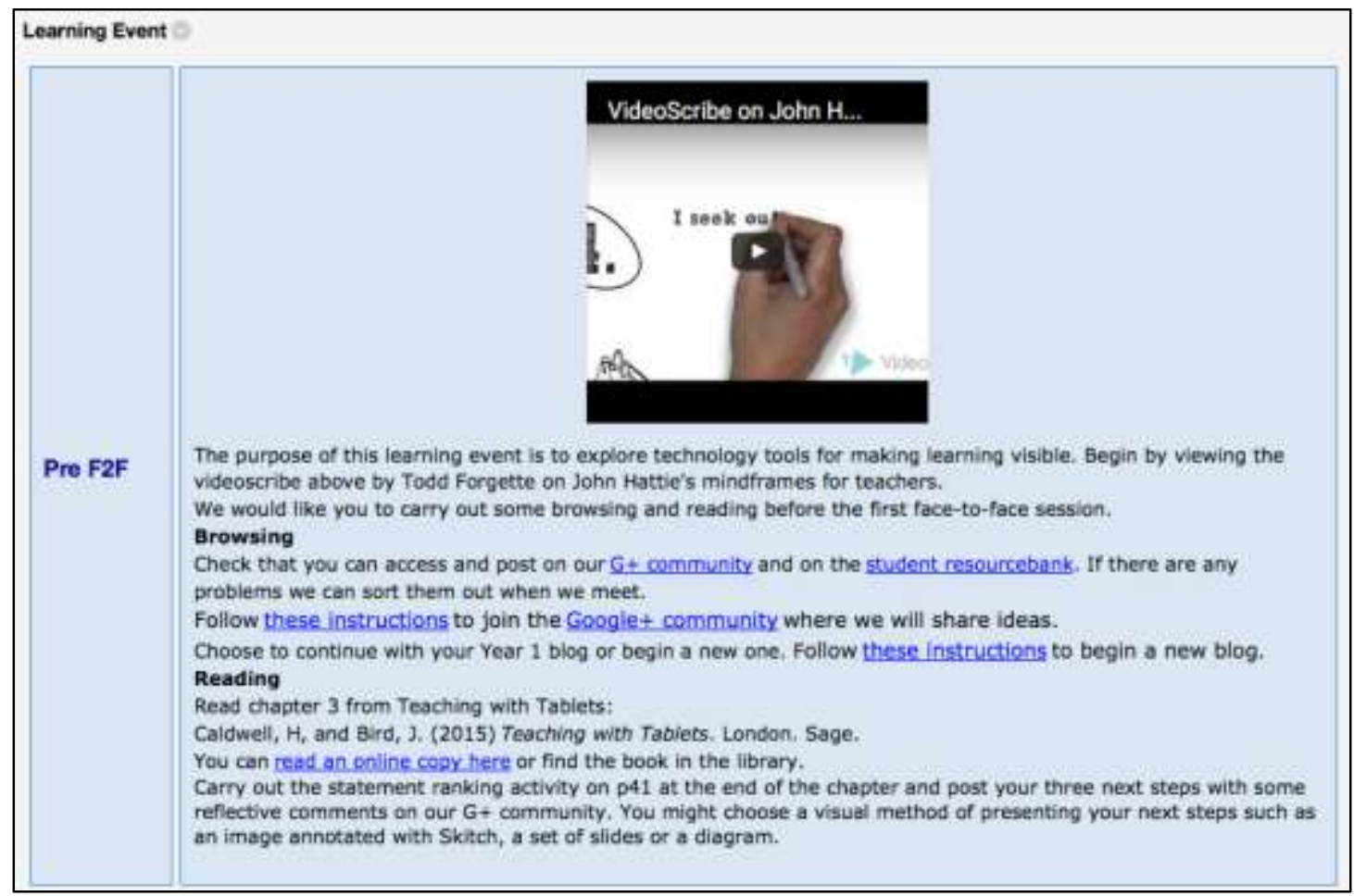

Figure 1: ITT module learning event (bit.ly/1SjIyDl)

You will see from this example that we are adopting a 'flipped' approach to our seminar sessions in which students undertake pre session tasks in order to build their skills and knowledge. The face-to-face sessions are used to encourage the active construction and application of knowledge, and students subsequently engage in some post session consolidation tasks. This approach separates the acquisition of knowledge from its application and assimilation (Mazur, 2012), freeing up the seminar sessions for more active participation. 
In this example the theme is visible learning and mobile devices are used to explore how a range of apps can help make pupils' learning journeys more explicit. This is followed by a post face-to-face task encouraging students to reflect about the application of the visible learning theme to their own teaching practice on their personal blogs and within an online Google+ community, and to comment on each others' posts. These posts and comments are submitted as evidence for their module assignment.

The Google+ community is used throughout the module as a space for capturing evolving ideas. Students post to this space before, during and after the seminar sessions using their mobile devices. In this instance, they annotated images using the app Skitch on their iPads in response to the pre-session reading and uploaded the results straight to the community for sharing in class. Class discussions are also documented straight onto the community via a chosen scribe and the collective knowledge then becomes a resource for completing students' individual blogposts. The use of the community space thus makes for a more seamless transition between the stages of the learning event. 


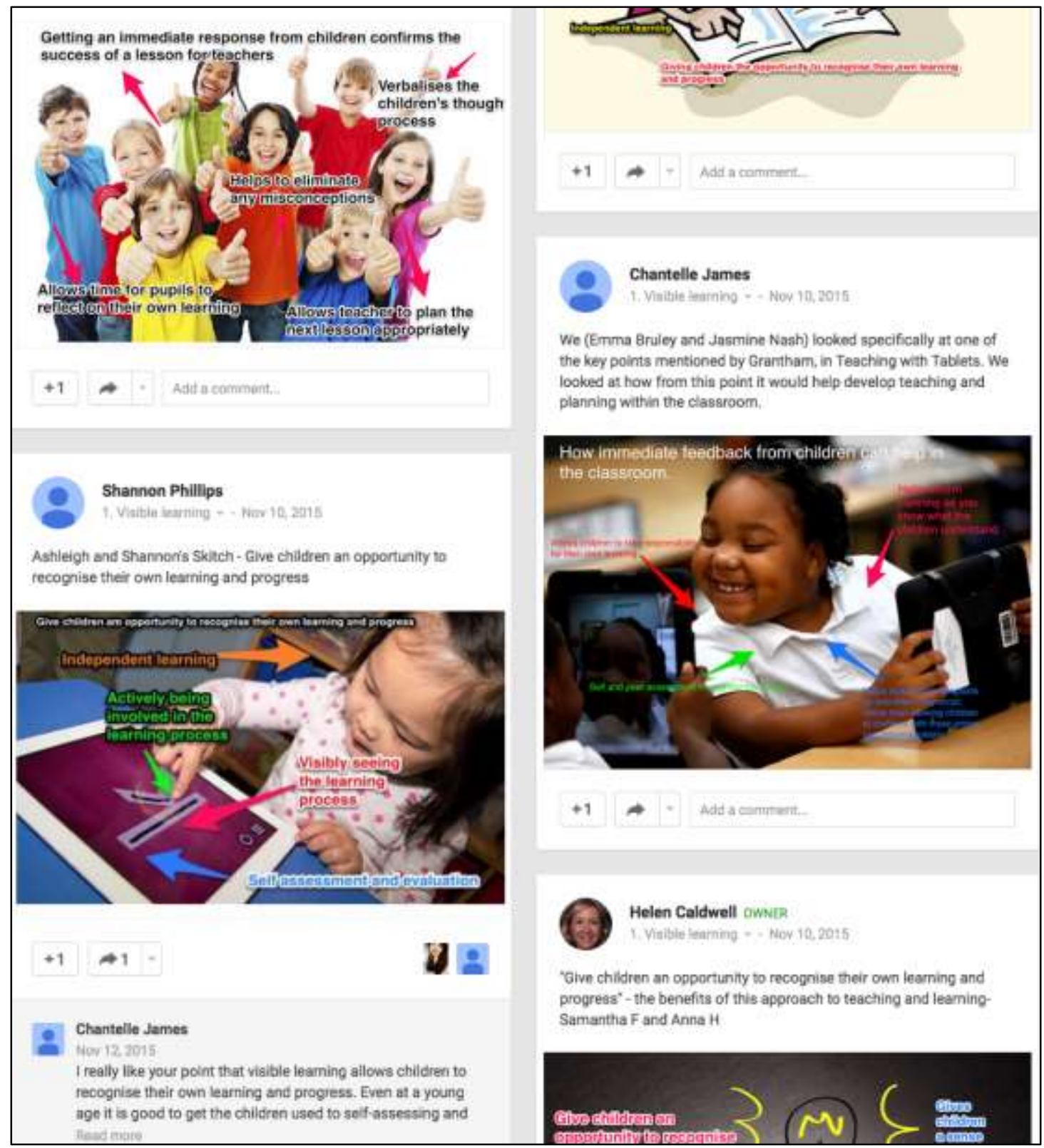

Figure 2: Visible learning posts on the G+ community (bit.ly/1UQKMYP)

\section{Example 2. Mobiles for manipulating media}

Looking at this example from a BA Primary Year 1 session on the theme of manipulating media, you will notice that the emphasis is on students using apps to create media-rich digital artefacts. The aims were to encourage students to think about developing pupils' digital literacy by expressing their understanding in different ways, and to offer visual and auditory routes for building subject knowledge. Through this activity students are gaining first hand experience of the sense of purpose that content sharing brings to learning. By posting to their public blogs and to the community, and then receiving comments from an authentic audience, students are continuing to interact beyond the face-to-face sessions. We 
are anticipating that they will gain the motivation and confidence to apply a similar approach in their own classrooms.

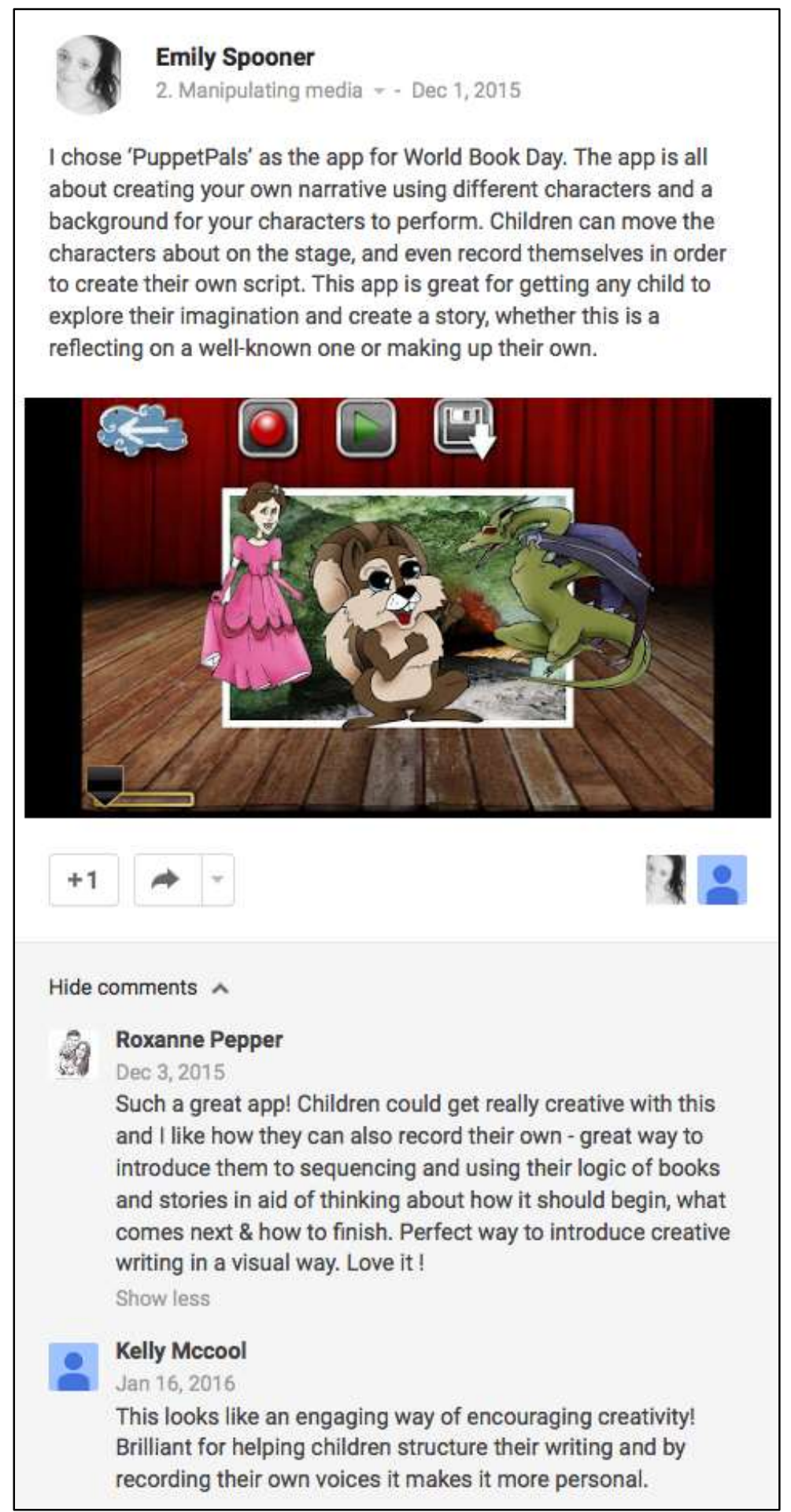

Figure 3: Manipulating media G+: (bit.ly/1JLTIOq) 


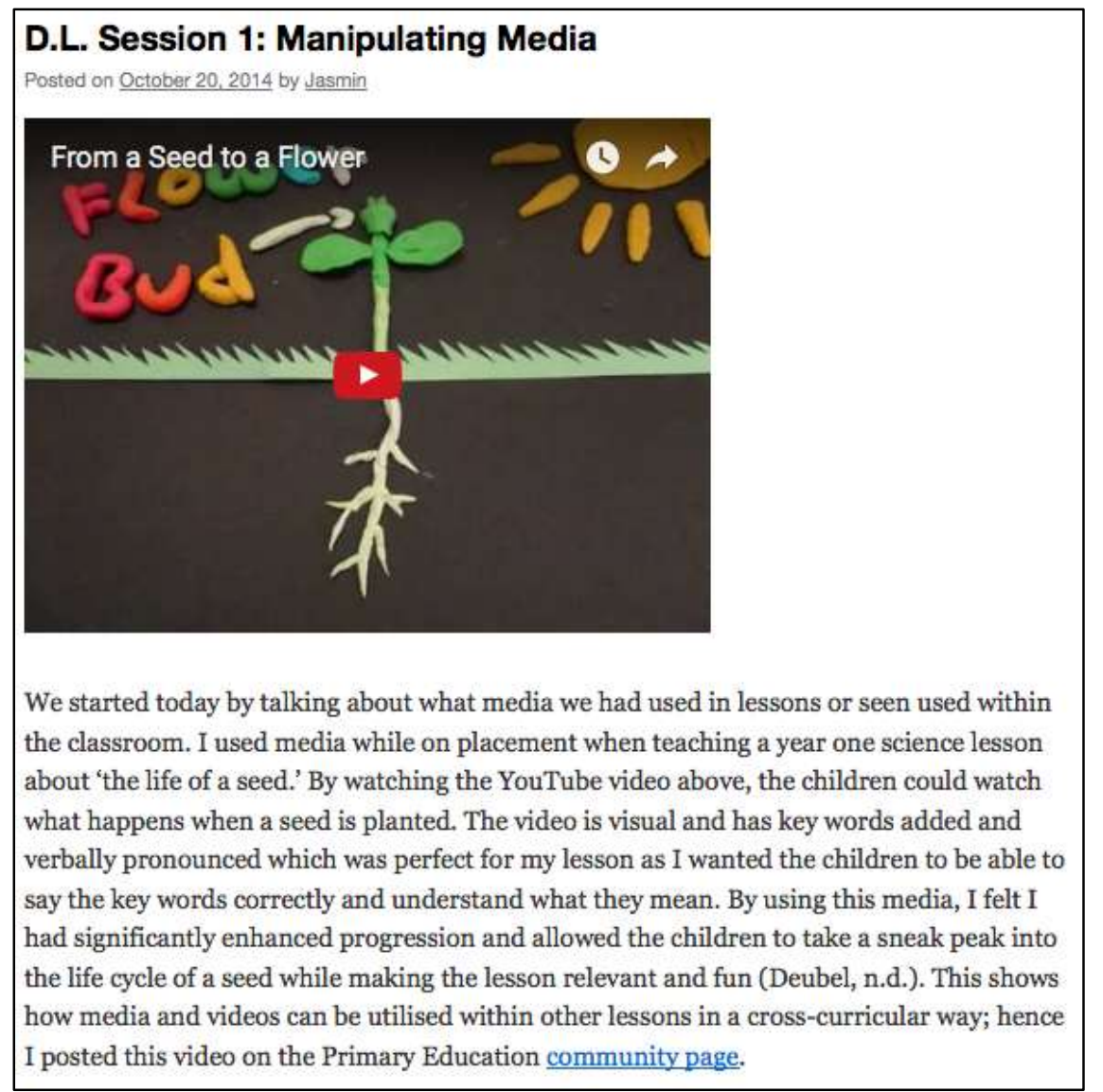

Figure 4: Student blogpost on manipulating media: (bit.ly/1mXzK8U)

\section{Example 3: Inclusive Creative Arts}

A further advantage of iPads in ITT is their ability to integrate readily with real world physical activities. Combining experiential learning with the creation of digital artefacts can enhance children's understanding of their environment (Ryu, 2008; Spikol, 2009), and it can integrate classroom learning with learning across physical and social spaces (Hwang et al. 2015). Hwang et al. summarise this process by saying, 'In such a seamless flipped learning environment, mobile devices and wireless communication facilitate the continuous flow of learning in different contexts, physical and social spaces.' (Hwang et al. p.456)

In this example, based on devising inclusive creative arts activities for SEN pupils, our students moved between digital and physical spaces in order to build understanding of how iPads can play a role in designing creative activities that are collaborative, personal, accessible and responsive. The use of iPads enabled them to remix ideas from a teacher CPD blog, digitise their own physical artwork and then collaborate by passing on work in progress using the idea of 'sketchbook circles'. The agility with which they could manipulate and share their evolving images using the iPads meant that they could create and share collaborative multimedia content all in the space of one two hour session. 


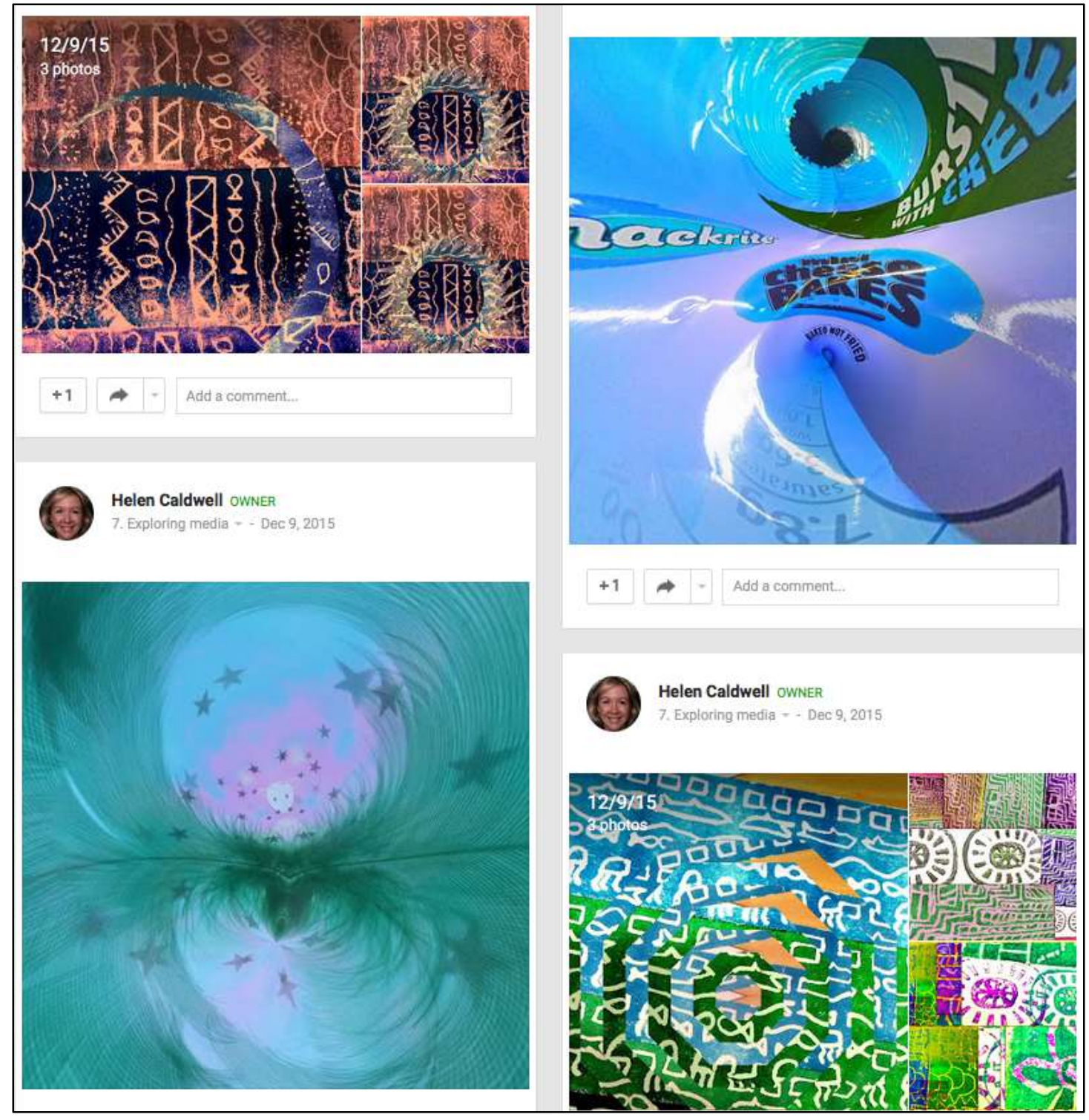

Figure 5: An inclusive creative arts seminar collaborating on digital and physical images

This group of students went on to further develop the theme of inclusive creative arts using multisensory apps and projected iPad images along with green screen techniques to create immersive environments for storytelling with children from a local special school (bit.ly/1Q7celM). Once again, it was the combination of physical and digital exploration of the world that lent weight to the learning experience. For the pupils, the fact that the session was captured as an iMovie meant that they could share it with their school community and review the ideas in order to build upon them. Similarly the students were able to use the film as a springboard to discuss which pedagogical strategies were most effective to take into their own practice. 


\section{EXAMPLES FROM PRACTICE: COLLABORATION BETWEEN TEACHERS, ACADEMICS, STUDENTS AND PUPILS}

Next, I will share experiences from mobile technology projects involving ITT students, primary school teachers and academics collaborating online and through face-to-face events.

\section{Example 1. Technology Outdoors}

A recent technology outdoors project focused on the use of mobile technologies away from the traditional learning spaces of classrooms and provided continuing professional development (CPD) for teachers to develop the resilience of pupils facing transitions to new learning phases or institutions. Activities such as augmented reality trails helped pupils manage change positively by socialising with their peer group and exploring the environment.

A cadre of volunteer student Digital Leaders was key to the success of the technology outdoors project. Digital Leaders are comfortable in the use of technology and are given the responsibility to help promote the effective use of technology within their settings (Twining, 2014; Passey 2013). The School of Education has piloted one of the first Digital Leader programmes in Higher Education over the last two academic years, with volunteers drawn from across the student population. These students engage in a range of mobile technology projects in ITT partnership schools and support at CPD events.

In the example below, student digital leaders worked alongside pupil digital leaders to create iMovie trailers based on a campus trail. The University and local schools benefit from the Digital Leader input, and the students themselves learn transferable skills that enhance their employability. 


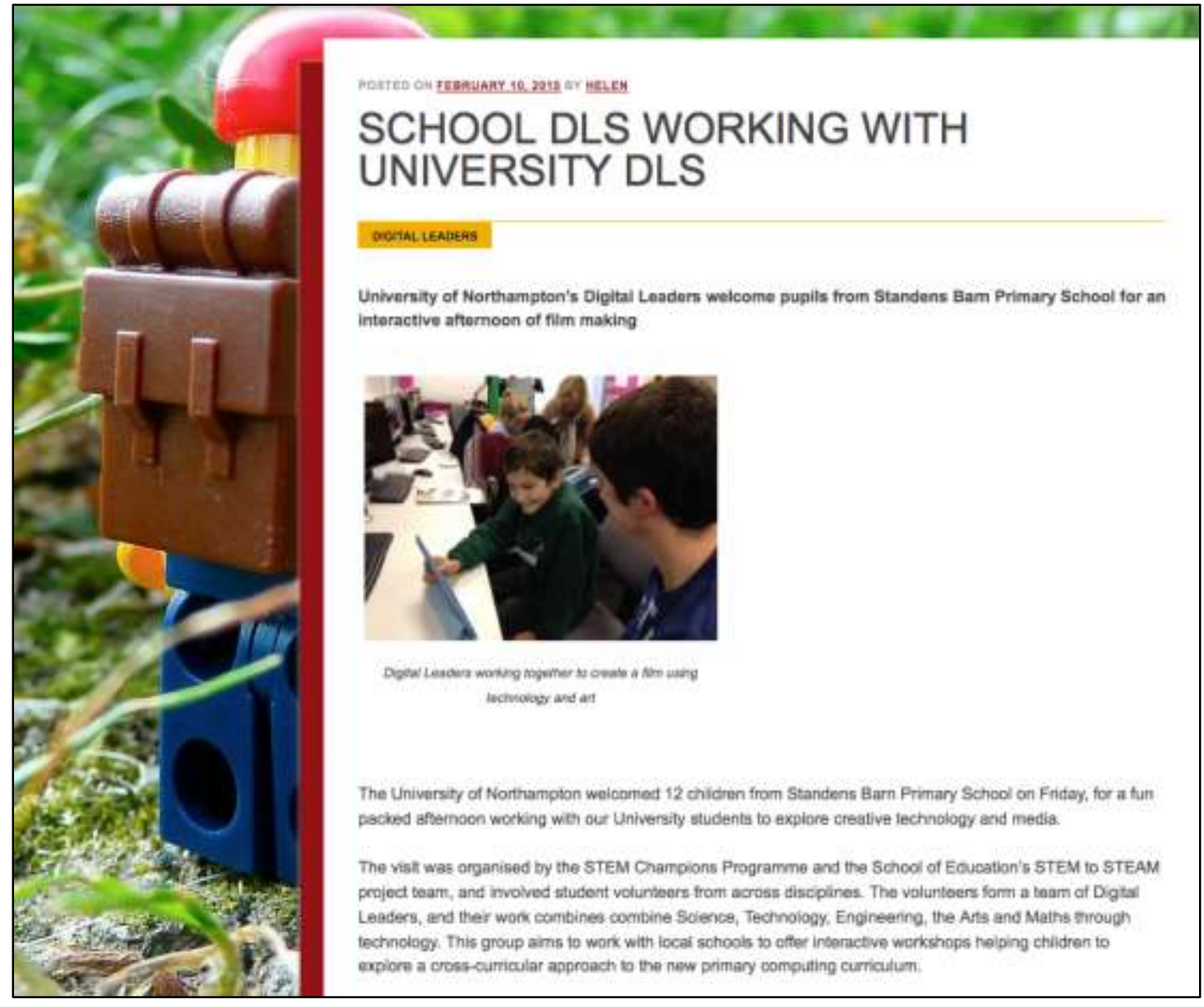

Figure 6: Digital Leaders exploring technology outdoors (bit.ly/1SNkjva)

\section{Example 2: Stem to SteAm}

The use of mobile technologies and digital media continues to rise in importance as a key cross-disciplinary skill. A goal of the Stem to SteAm project was to develop and test an approach to developing visual culture via an Educators' Forum for the creative exploration of the arts and technology in the Primary curriculum. Academics and teachers shared strategies in the use of mobile technologies through face-to-face workshops and populated an open online space with a repository of resources and reflections. An outcome was a series of media day videos capturing innovative practice with media techniques (bit.ly/1KeJD7u).

Once again, a key aspect of this project was the combination of online initiatives supporting mobile pedagogies such as project blogs and communities, together with face-to-face initiatives such as Teachmeets that brought together teachers, academics, students and pupils. 


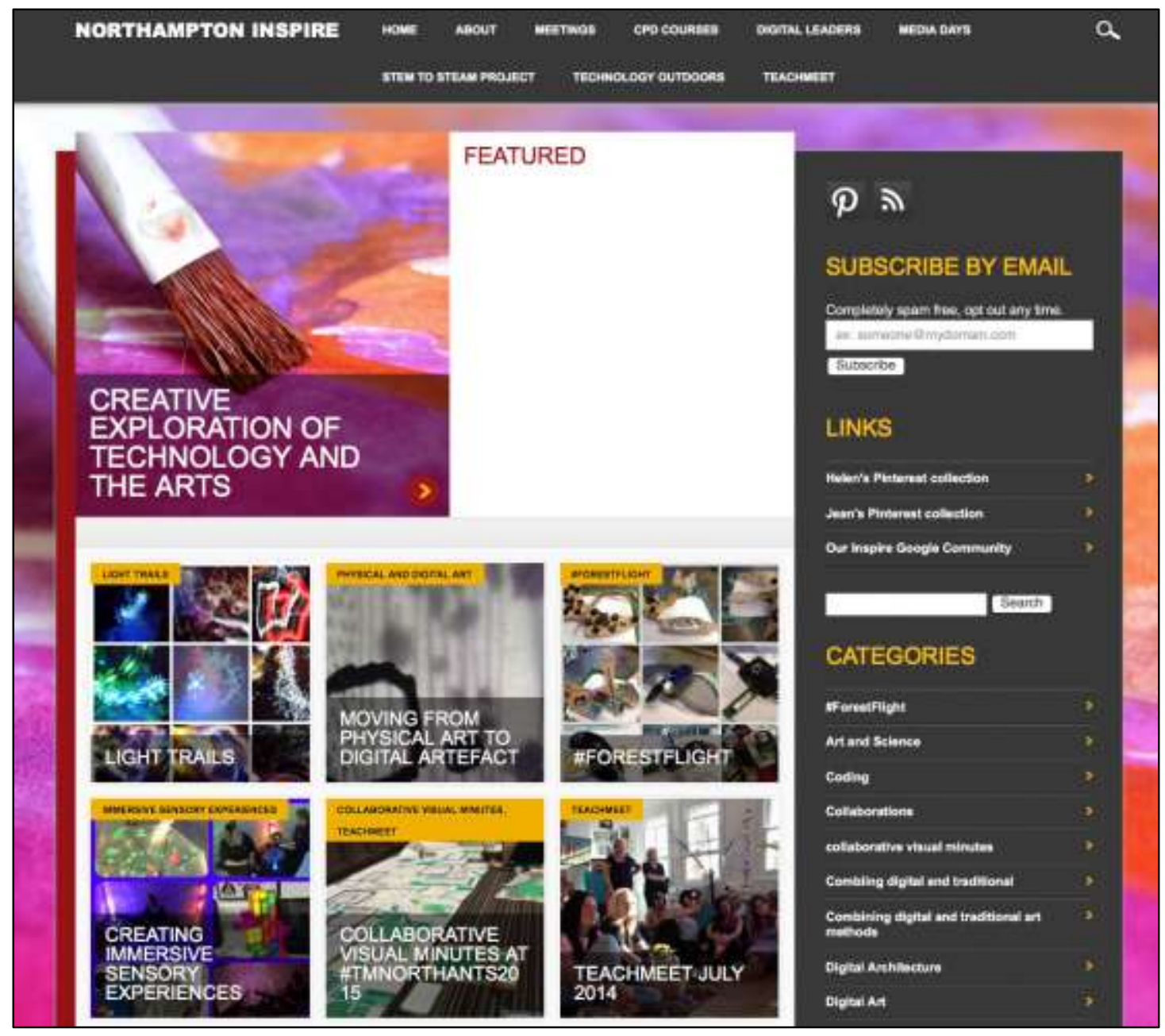

Figure 7: Northampton Inspire project blog (https://mypad.northampton.ac.uk/inspire) 


\section{USING IPADS TO CAPTURE A CPD EVENT}

iPads were used in a number of ways to capture and share our recent TeachMeet Northampton event.

Firstly, short voxpops of attendees sharing their thoughts on the computing curriculum were collected by Leon

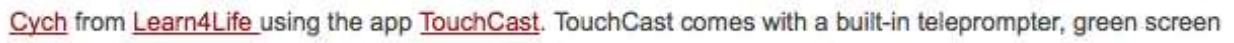
effects and many other options. If you combine this with a good microphone, lights and a portable green screen you can make broadcast quality videos directly from an iPad. Notice in the first video below that you can also embed webpages and interactive content so that the videos themselves are browsable.

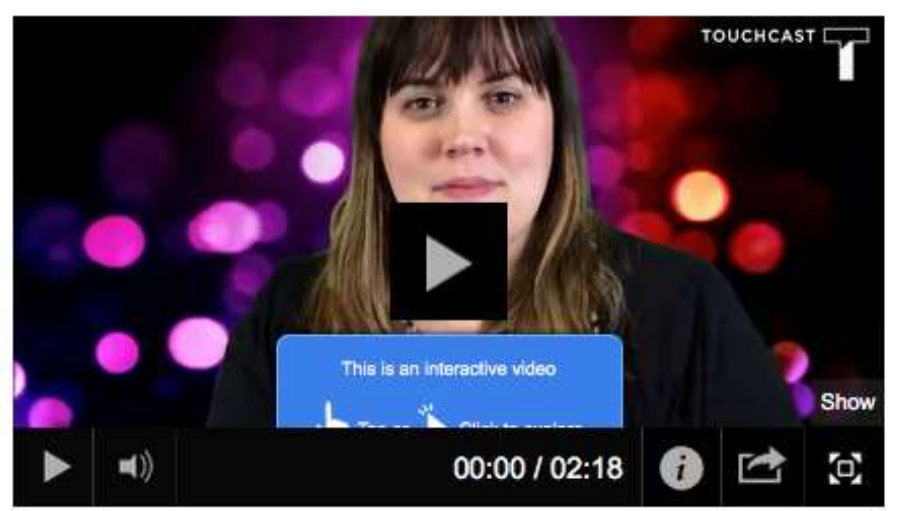

Figure 8: Using iPads to capture a CPD event (bit.ly/1 V6TgOZ)

\section{EXAMPLES FROM PRACTICE: ACADEMICS USING IPADS}

\section{Example 1. Apps for Innovation project}

In 2014/15 a group of academics piloted the use of iPads to enhance learning and teaching within the School of Education. An example of the cross-pollination of ideas that occurred via their online community space (Wick, 2000) can be seen around a set of apps for art activities bringing together the 'app smashing' combination of Rollworld, Fragment, BeFunky. These apps were repeatedly explored in a number of different teaching contexts, resulting in an evolution of teaching ideas through posts and comments on the project blog and online community. Through this process, the group developed shared metacognition (Gunawardena et al., 2009; Mason \& Rennie, 2008) around the use of iPads in a Higher Education context. A core set of more open-ended content-creation apps gradually emerged as academics trialled them for different purposes and recorded successes as mini case studies on the blog and online community. Around 25 core apps were identified during the pilot year as being particularly relevant to develop 
staff and student digital literacy ${ }^{1}$. These core apps focused on the themes of creation, collaboration, curation, capture and productivity.

In 2015/16 a much wider group of students and staff are building upon the pilot group experiences so that mobile learning becomes embedded in the School of Education modules, programmes and practice. In addition, a team of academics designed a Teaching with Tablets MOOC, which had 570 enrolments in February 2016. A 'hybrid' MOOC design combined structured content with an online learning community, with the aim of helping educators at all levels make effective use of iPads and tablets. It forms an Open Educational Resource (OER) that can be repurposed for future CPD and teacher education programmes.

${ }^{1}$ School of Education core apps 2015: Adobe Voice, Socrative, Turnitin, Picollage, Pinterest, Scan, Haikudeck, Thinglink, Book creator, Padlet, Skitch, Google drive, iMovie, Panopto, YouTube, iNorthampton, Explain Everything, Popplet Lite, Post-it Note Plus, Prezi, Kaltura, Google docs, iMovie, GarageBand, Pages, Numbers, Keynote, iTunes U 


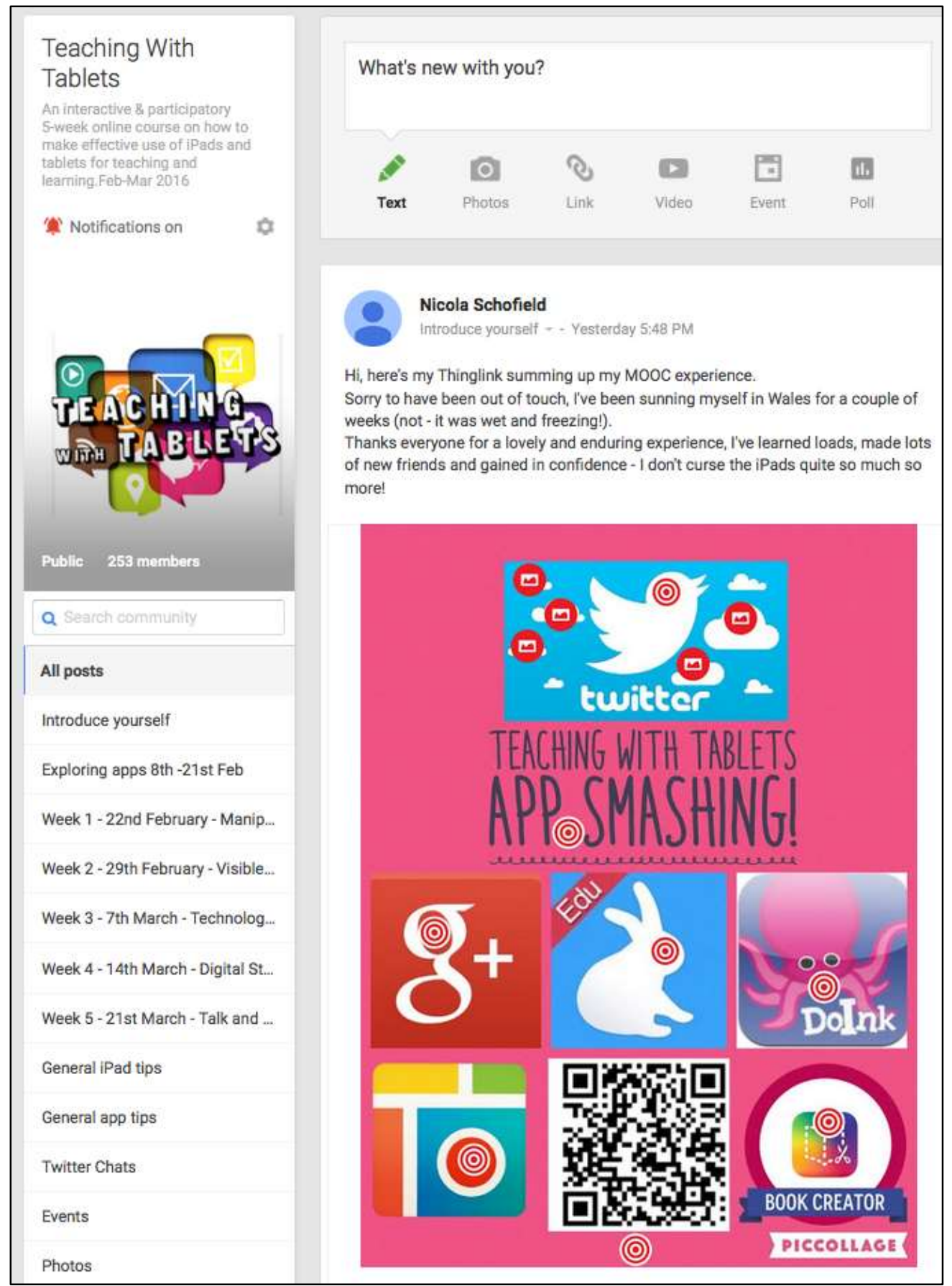

Figure 9: Teaching with Tablets MOOC online community (bit.ly/1S7UqTI)

Alongside the course content delivered through the Blackboard Open Education platform, the online learning community provided a connected environment for the MOOC participants to co-construct an evidence base of best practice in teaching with tablets.

\section{SUMMARY}

Together, our face-to-face and online initiatives in mobile learning illustrate how mobile technologies have been a catalyst for new pedagogies in our teacher 
education programmes at the University of Northampton. We aim to develop creative self-directed learners who can work in collaborative teams within a professional community of teachers, academics and students. With this in mind, we are moving in the direction of informal, networked, technology-enabled learning, which extends learning beyond our face-to-face sessions. To this end, we are focusing on a set of core apps that enable students to make shareable digital artefacts, and that facilitate the creation, collaboration, curation, and capture of content.

To summarise, our examples from practice have demonstrated that mobile technologies can act as a catalyst for pedagogic innovation by providing:

- enhanced opportunities to develop shared understandings of content and pedagogy in a social environment

- a bridge between formal and informal learning and across disciplines

- first hand experience of the sense of purpose that content sharing can bring to learning

- contextualised experiential learning opportunities that combine real world interaction with the creation of digital artefacts

- captured teaching events as a springboard to discuss which pedagogical strategies are most effective

- opportunities to revisit learning, making for a smooth transfer of pedagogy to practice

- multimodal learning journeys that move in and out of physical and social learning spaces, a cyclical process that increases the cross-pollination of ideas

\section{CONCLUSION}

By giving learners control over the time, pace and place of their learning, and by providing opportunities for authentic engagement with the physical world, the iPads have acted as a bridge between formal and informal learning, and across disciplines in primary education. This process has been facilitated by a combination of online learning communities and face-to-face learning events.

Within the online communities our pre and in-service teachers have coconstructed knowledge by documenting learning that took place in a number of different contexts: at teacher sharing events, at network meetings, in classrooms, and via hands-on activities. This makes a case for 'multimodal learning', which mixes physical interaction with asynchronous learning (Hammond, 1998). Mobile devices can thus enable learning journeys to move in and out of a number of 'digital habitats' (Wenger, White and Smith, 2009).

The emphasis on social learning has multiplied learning opportunities and has led to the development of a shared common purpose between academics, pre- and inservice teachers. In this way, mobile technologies have the potential to prompt social transformation leading to innovative pedagogical practice. 
Our example cases also demonstrate that apps that allow for collaborative content creation have enabled a natural learning process that arises out of social behaviour and engagement with the world. As a result of this, we acknowledge the need to embed the use of technology in educational contexts through interdisciplinary approaches mixing physical, digital and social learning spaces.

Whilst hard research evidence from our iPad journeys has yet to be analysed, we are confident that mobile technologies combined with online learning communities in this way can provide a fertile ground for social learning. Our ongoing anecdotal experience shows that the introduction of mobiles has been a catalyst in fostering pedagogical innovation within our university's teaching and learning communities.

Our longer-term aim is to systematically evidence the impact of our mobile learning journeys in order to deepen our understanding across a combination of locations, times, technologies and social settings in higher education, and thereby to identify and evidence their effects on student learning. 


\section{REFERENCES}

Alberta, (2012) iPads - What are we learning? [online]. Available from: http://education.alberta.ca/admin/technology/research.aspx [Accessed: 18 Jan 2014].

Berger, P., \& Luckman, T. (1966). The Social Construction of Reality. Anchor Books.

Bertarelli F., Corradinii M., Guaraldi. F,. Fonda S., \& Genovese, E. (2011). Advanced learning and ICT: new teaching experiences in university setttings. International Journal of Technology Enhanced Learning 3(4) 377.

Burden, K., Hopkins, P., Male, T., Martin, S., and Trala, C. (2012) iPad Scotland Evaluation iPad Scotland Evaluation. [online]. Available from: http://www2.hull.ac.uk/ifl/ipadresearchinschools.aspx [Accessed: 18 Jan 2014].

Caldwell, H. \& Bird, J. (2015). Teaching with Tablets. London: Sage.

Caldwell, H. and Heaton, R. (2015). The interdisciplinary use of blogs and online communities in higher education. Paper presented to the International Conference of Information Technology in Education (ICICTE), Kos, July 2015.

Chandra, V. \& Mills, K. (2015). Transforming the core business of teaching and learning in classrooms through ICT. Technology, Pedagogy and Education. 24(3), 285-301.

Clarke, B. (2012) One-to-one Tablets in Secondary Schools : An Evaluation Study. [online]. Available from: http://tabletsforschools.org.uk/wpcontent/uploads/2012/12/2011-12-Final-Report.pdf [Accessed: 18 Jan 2014].

Conole, G. (2013). MOOCs as disruptive technologies: strategies for enhancing the learner experience and quality of MOOCs. Revista de Educación a Distancia, 39, 1-17.

Cope, B. and Kalantzis, M., 2008. Ubiquitous learning: An agenda for educational transformation. Proceedings of the 6th Networked Learning, Greece.

Danaher, P., Gururajan, R. and Hafeez-Baig, A., 2009. Transforming the practice of mobile learning: promoting pedagogical innovation through educational principles and strategies that work. In Ryu, H. ed., 2008. Innovative Mobile Learning: Techniques and Technologies: Techniques and Technologies. IGI Global. pp21-46.

Denning, P.J., 2004. The social life of innovation. Communications of the ACM, 47(4), pp.15-19. 
Gannon-Leary, P., \& Fontainha, E. (2007). Communities of Practice and virtual learning communities: benefits, barriers and success factors. Barriers and Success Factors. eLearning Papers, (5).

Gulbrandsen M. \& Aanstad S. (2014) Is innovation a useful concept for arts and humanities research? In, Fagerberg J, Mowery D., Nelson RR (eds) The Oxford handbook of innovation. Oxford University Press, Oxford.

Hammond, M. (1998). Learning through online discussion. Journal of Information Technology for Teacher Education, 7(3), 331-346.

Heinrich, P. (2012) The iPad as a Tool for Education NAACE and 9ine Consulting [online]. Available from:

http://www.naace.co.uk/get.html?_Action=GetFileand_Key=Data26613and _Id=1965_Wizard=0and_DontCache $=1341555048$ [Accessed: 18 Jan 2014].

Henderson, S. and Yeow, J. (2012) iPads in Education - A case study of iPad adoption and use in a primary school. In HICSS '12 Proceedings of the 2012 $45^{\text {th }}$ Hawaii International Conference on System Sciences, pp 78 - 87.

Higgins, S. ZhiMin, X. and Katsipataki, M (2012). The impact of digital technology on learning. Education Endowment Foundation.

Hung, D. (2002). Situated cognition and problem-based learning: implications for learning and instruction with technology. Journal of Interactive Learning Research, 13.4, 393-415.

Hwang, G.J., Lai, C.L. and Wang, S.Y., 2015. Seamless flipped learning: a mobile technology-enhanced flipped classroom with effective learning strategies. Journal of Computers in Education, 2(4), pp.449-473.

Johnson, C. M. (2001). A survey of current research on online Communities of Practice. The Internet and Higher Education, 4.1, 45-60.

Kong, S. C., \& Song, Y. (2015). An experience of personalized learning hub initiative embedding BYOD for reflective engagement in higher education. Computers \& Education, 88, 227-240.

Livingstone K. (2014). Teacher educators: hidden professionals? European Journal of Education 49(2) 218.

Luckin, R., Clark, W., Garnett, F., Whitworth, A., Akass, J., Cook, J., \& Robertson, J. (2010). Learner-Generated Contexts: A Framework to Support the Effective. Web 2.0-Based E-Learning: Applying Social Informatics for Tertiary Teaching: Applying Social Informatics for Tertiary Teaching, 70. 
Markham, T. (2003). Project based learning handbook: A guide to standardsfocused project based learning for middle and high school teachers. California: Buck Institute for Education.

Mason, R. \& Rennie, F. (2008). Social networking as an educational tool. Elearning and social networking handbook: Resources for higher education, $1-24$.

Mazur, E. (2012) 'The scientific approach to teaching: research as a basis for course design.' YouTube. [online]. Available from: https://www.youtube.com/watch?v=aYiI2Hvg5LE

Melhuish, K., and Falloon, G. (2010) Looking to the future: M-learning with the iPad. Computers in New

Zealand. Schools: Learning, Leading, Technology. 22 (3).

Moats, L. (2014). What teachers don't know and why they aren't learning it: addressing the need for content and pedagogy in teacher education. Australian Journal of Learning Difficulties 19(2) 75-91.

Nkuyubwatsi, B. (2013) Evaluation of Massive Open Online Courses (MOOCs) From the Learner's Perspective, Proceedings of the $12^{\text {th }}$ European Conference on e-Learning ECEL-2013, 2, 340-346, also available from https://lra.le.ac.uk/handle/2381/28553

Oliver, R., \& Herrington, J. (2000). Using situated learning as a design strategy for Web-based learning. Instructional and cognitive impacts of web-based education, 178-191.

Ozturk, H. T., \& Ozcinar, H. (2013). Learning in multiple communities from the perspective of knowledge capital. The International Review of Research in Open and Distributed Learning, 14(1), 204-221.

Pachler, N., Cook, J., \& Bachmair, B. (2010). Appropriation of mobile cultural resources for learning. International Journal of Mobile and Blended Learning (IJMBL), 2(1), 1-21.

Passey, D. (2013). inspire-Wolverhampton's local education partnership: Evaluating the development and practices of digital leaders in Wolverhampton schools.

Pegrum, Mark, Christine Howitt, and Michelle Striepe (2013). "Learning to take the tablet: How pre-service teachers use iPads to facilitate their learning." Australasian Journal of Educational Technology 29.4 (2013).

Puentedura, R. (2006). Transformatiom, Technology, and Education. Presentation given August 18, 2006 as part of the Strengthening Your District Through Technology workshops, Maine, US. Available at: http://hippasus.com/resources/tte/part1.html [Accessed 27 Aug 2015]. 
Richardson, W. (2010). Blogs, wikis, podcasts and other powerful web tools for classrooms. Thousand Oaks, CA: Corwin.

Ryu, H. ed., 2008. Innovative Mobile Learning: Techniques and Technologies: Techniques and Technologies. IGI Global.

Selwyn, N. (2007) The use of technology in university teaching: a critical perspective Journal of Computer Assisted Learning 23(2) 83-94.

Song, Y. J. (2014). "Bring Your Own Device (BYOD)"' for seamless science inquiry in a primary school. Computers \& Education, 74, 50-60.

Spikol, D. (2009). Collaboration in Context as a Framework for Designing Innovative Mobile Learning Activities. In H. Ryu, \& D. Parsons (Eds.) Innovative Mobile Learning: Techniques and Technologies (pp. 172-196). Hershey, PA: Information Science Reference. doi:10.4018/978-1-60566062-2.ch009.

Tamin, R., Bernard, R., Borokhovski, E., Abrami, P and Schmid, R. (2011) What forty years of research says about the impact of technology on learning: a second-order meta analysis and validation study. Review of Educational Research 81(1) 4-28.

Twining, P. (2014). Redefining Education: 1: 1 computing strategies in English schools. Change, 2(6), 21.

Twining, P., Davis, N., Charania, A., Chowfin, A., Henry, F., Nordin, H., \& Woodward, C. (2015). Developing New Indicators To Describe Digital Technology Infrastructure In Primary And Secondary Education. Open Research Online.

Wenger, E. and Lave, J., 1991. Situated Learning: Legitimate Peripheral Participation (Learning in Doing: Social, Cognitive and Computational Perspectives) by. Cambridge University Press, Cambridge, UK.

Wenger, E. (2011). Communities of Practice: A brief introduction.

Wenger, E., White, N. and Smith, J.D., 2009. Digital habitats: Stewarding technology for communities. CPsquare.

Wick, C. (2000). Knowledge management and leadership opportunities for technical communicators. Technical Communication, 47.4, 515-529. 